\title{
B-cell receptor-associated protein 31 promotes migration and invasion in ovarian cancer cells
}

\author{
HAIYAN LIANG ${ }^{1}$, JIQIAO DONG $^{2}$, ZIYAN CHENG $^{3}$, QIAN LI $^{1}$, DINGQING FENG $^{1}$ and BIN LING ${ }^{1}$ \\ ${ }^{1}$ Department of Gynecology and Obstetrics, China-Japan Friendship Hospital, Beijing 100029; ${ }^{2}$ GeneX Health Life Co., Ltd., \\ Beijing 100195; ${ }^{3}$ The Experimental High School Attached To Beijing Normal University, Beijing 100032, P.R. China
}

Received October 13, 2020; Accepted May 10, 2021

DOI: $10.3892 / \mathrm{etm} .2021 .10290$

\begin{abstract}
B cell receptor associated protein 31 (BAP31) is a member of the $\mathrm{B}$ cell receptor that functions as a transporter for numerous types of newly formed proteins from the endoplasmic reticulum to the Golgi apparatus. Previous studies found that that BAP31 serves an important role in the pathogenesis of malignancy but its specific effect on ovarian cancer is not clear. The present study aimed to investigate whether BAP31 affects ovarian cancer and its underlying mechanism. In the present study, ovarian cancer tissue, human ovarian normal epithelial cell line IOSE80 and five ovarian cancer cell lines (A2780, Hey-T30, COC1, SKOV3 and OVCAR3) underwent reverse transcription-quantitative PCR, western blotting, Cell Counting Kit-8, Transwell and co-immunoprecipitation (Co-IP) assay and transcriptome sequencing. Previous studies showed that compared with healthy tissues, the expression level of BAP31 protein was found to be significantly higher in various types of cancer tissues, implying that BAP31 may serve an important role in the pathogenesis of cancer. The present study found that BAP31 expression was upregulated in five ovarian cancer cell lines and ovarian cancer tissue, such that BAP31 knockdown [performed using two short hairpin (sh)RNA plasmids] decreased proliferation, invasion and migration. In addition, BAP31 knockdown was found to downregulate the expression of $\mathrm{N}$-cadherin and upregulate the expression of E-cadherin on transcriptional level by controlling the nuclear aggregation of TWIST1, a transcriptional regulator of $\mathrm{N}$-cadherin and $\mathrm{E}$-cadherin. There was no interaction between BAP31 and E-cadherin or N-cadherin using Co-IP detection, while BAP31, E-cadherin and N-cadherin interacted with TWIST1 protein. E-cadherin and N-cadherin expression levels recovered when TWIST1 was overexpressed
\end{abstract}

Correspondence to: Dr Dingqing Feng or Dr Bin Ling, Department of Gynecology and Obstetrics, China-Japan Friendship Hospital, 2 Yinghuayuan East Street, Beijing 100029, P.R. China

E-mail: dingqing_feng@yahoo.com

E-mail: lingbin.ling@vip.sina.com

Key words: B-cell receptor-associated protein 31, ovarian cancer, $\mathrm{N}$-cadherin, E-cadherin, TWIST1 in the shBCAP31 cells. These results suggest that BAP31 can regulate the migration and invasion of ovarian cancer cells through the epithelial-mesenchymal transition pathway at the transcriptional level, which may be beneficial for the identification of potentially novel targets for ovarian cancer therapy.

\section{Introduction}

Ovarian cancer is a common malignancy of the female reproductive system with a high mortality rate (1). In the USA, $>15,000$ patients die of ovarian cancer and there are 20,000 new diagnosed patients each year (2). The most common type of ovarian cancer is epithelial ovarian cancer, also known as ovarian carcinoma (3). Due to the lack of effective screening methods, patients are frequently already in the advanced stages of ovarian cancer at the time of diagnosis, where extensive metastasis into the abdominal cavity is the main cause of mortality $(4,5)$. The 5-year survival rate of patients with ovarian cancer remains only at $60 \%$ though progress has been made in the development of novel chemotherapeutic strategies (6). Therefore, it is important to understand the process of ovarian cancer tumorigenesis and metastasis on a deeper level. In the study of the basic underlying mechanism underlying ovarian cancer progression, it was previously found that alterations in the expression profiles of cytokines, such as VEGF and TNF- $\alpha$, can be used to reflect the status of abnormal proliferation or apoptosis in ovarian germinal epithelial cells, where they can contribute to the occurrence and development of ovarian cancer cells (7).

B cell receptor associated protein 31 (BAP31 for protein; BCAP31 for gene) was first identified by Kim et al (8) in 1994. Due to its selective binding to membrane immunoglobulin $\mathrm{D}$, it is considered to be a member of the $\mathrm{B}$ cell receptor $(9,10)$. There are two primary functions of the BAP31 protein: i) To mediate the transport of numerous types of newly formed proteins from the endoplasmic reticulum (ER) to the Golgi apparatus as a carrier molecule (10); and ii) to regulate apoptosis. In particular, BAP31 is involved in regulating apoptosis mediated by Bcl-2 and Bcl-XL (11). The BCAP31 gene is located in the q28 open reading frame of the $\mathrm{X}$ chromosome that is 738-bp in length and encodes 246 amino acids. The molecular weight of the mature BAP31 protein product is $28 \mathrm{KDa}(9,10)$. BAP31 is an endoplasmic reticulum (ER) protein where its N-terminus is located in the ER lumen and contains three transmembrane 
domains, which serve to promote anchoring to the ER $(11,12)$. By contrast, the C-terminus is located in the cytoplasm, where it mediates protein-protein interaction and is the area where BAP31 mainly performs its protein transport and apoptosis regulation functions $(11,12)$. As a carrier protein, BAP31 serves an important role in apoptosis $(11,13)$. Compared with those in adjacent non-cancerous tissues, the expression levels of BAP31 protein were persistently found to be significantly upregulated in malignant melanoma, hepatocellular carcinoma or cervical cancer tissues (14-16). These previous observations suggested that BAP31 may serve an important role in the pathogenesis of malignancies. In particular, it has been previously demonstrated that BAP31 may be an ideal target for immunotherapy of malignant melanoma (14). The expression levels of BAP31 in colorectal cancer has also been found to be positively associated with the degree of liver metastasis. However, the survival rate of patients with colorectal cancer with lower expression levels of BAP31 is significantly lower (17). In addition, BAP31 expression has been revealed to be upregulated during the progression of cervical cancer into the metastatic stages (16-18). However, the expression profile and role of BAP31 in ovarian cancer remain unknown.

Epithelial-to-mesenchymal transition (EMT) is a developmental cell program that naturally occurs in a broad range of tissue types and developmental stages (19). During EMT, epithelial cells temporarily could lose their cell polarity and exhibit the characteristics of mesenchymal cells with increased migratory and invasive phenotypes (20). Downregulation of E-cadherin expression and the concomitant upregulation of $\mathrm{N}$-cadherin expression are considered to be key events during EMT (21). Downregulation of E-cadherin expression has been found in esophageal and prostate cancer $(22,23)$. The internal-to-external signaling mechanism that regulates the adhesive activity of E-cadherin present on the cell surface is important in cancer $(13,24)$. Loss of cell adhesion and cell junctions formed by E-cadherin anchoring allows cells to detach from the primary tumor, invade surrounding tissues and migrate to distant tissues (24). Previous studies have demonstrated the role of E-cadherin and $\mathrm{N}$-cadherin in non-small cell lung, colorectal and pancreatic cancer and melanoma invasion and metastasis and how they synergistically contribute to signaling pathways involved in EMT (21), such as TGF- $\beta(13,25)$, MAPK (26) or JAK/STAT (27). Compared with the suppressive role of E-cadherin on cell migration, $\mathrm{N}$-cadherin enhances the migration and invasion of tumor cells, irrespective of the expression of E-cadherin (28). Numerous previous studies found that increased expression of $\mathrm{N}$-cadherin can enhance the migratory and invasive capabilities of multiple types of cancer cells in vivo and in vitro, such as bladder (29) and pancreatic cancer (30).

The transcriptional inhibition of E-cadherin and the upregulation of $\mathrm{N}$-cadherin i.e. the cadherin switch is considered to be a marker of EMT (21). This is mediated by transcription factors (TFs), including the snail family (Snai1, Snai2/Slug and Snai3/Smuc), zinc finger E-box-binding homeobox 1 (Zeb)1, Zeb2 proteins, TWIST1 and TWIST2 (31). TWIST is essential for a number of biological processes, including myogenesis (32), osteogenesis (33) and neurogenesis (34). In addition to its role in normal physiological development, TWIST has also been found to be upregulated in a number of cancer types, such as breast and lung cancer $(35,36)$. In these cancer types, TWIST expression is associated with poor prognosis, higher grade tumors and more invasive and metastatic phenotypes (31). Vertebrate animals express two types of TWIST, which encode two similar proteins that share $90 \%$ homology, named TWIST1 AND TWIST2 (37). TWIST1 serves an important role in cell migration and tissue reorganization during embryo formation (38). Studies have previously reported that the Twist1 gene and its expression products are expressed in a variety of tumor tissues and cells, including rhabdomyosarcoma, breast cancer, gastric cancer, fibroblastoma, glioma and pancreatic adenocarcinoma (39-41). Activated Twist enhances the migration and invasion of cells by upregulating $\mathrm{N}$-cadherin whilst downregulating E-cadherin (42).

Based on all the aforementioned findings, BAP31 may serve an important role in the progress of cancer; however, its function in ovarian cancer is not clear. The present study investigated the role of BAP31 involved in ovarian cancer cell invasion and its underlying mechanism. A BAP31 knockdown model was established, and cell proliferation, migration and invasion ability was assessed. In addition, downstream genes of BAP31were investigated to elucidate the underly mechanisms.

\section{Materials and methods}

Clinical samples. The present study was approved by the Ethics Committees of China-Japan Friendship Hospital (approval no. 2020-28-K20; Beijing, China) and written informed consents were obtained from all participants. Frozen resected surgical tissue from 10 female patients with ovarian cancer with an average age of $59.1 \pm 8.3$ years old were enrollment from June 2018 to March 2020 collected from Department of Gynecology and Obstetrics, China-Japan Friendship Hospital (Beijing, China). All pathological specimens collected during primary surgery or before neoadjuvant chemotherapy were analyzed by an expert gynecological pathologist according to the guidelines of the World Health Organization (WHO) International Classification of Ovarian Tumors (43). The inclusion and exclusion criteria are as follows: Inclusion criteria: Patients with complete clinical data. Exclusion criteria: i) Patients who received chemotherapy or radiation therapy and ii) patients with missing clinical data. None of the patients recruited in the present study received chemotherapy or radiation therapy before the specimens were collected.

Immunohistochemistry (IHC). A total of 10 tissue samples from patients with ovarian cancer were immersed in $4 \%$ paraformaldehyde for $4 \mathrm{~h}$ at room temperature and assembled into a tissue microarray (diameter, $2 \mathrm{~mm}$ ). After cutting to a thickness of $5 \mu \mathrm{m}$, paraffin sections were deparaffinized in xylene for 5 min twice, followed by hydration in a descending ethanol series (100, 100, 90, 80 and 70\%), and rinsed in distilled water. The paraffin sections were heat-treated with EDTA antigen retrieval solution (pH, 8.0; cat. no. ZLI-9079; OriGene Technologies, Inc.) for $20 \mathrm{~min}$ at $98^{\circ} \mathrm{C}$ Paraffin sections were incubated in $3 \%$ hydrogen peroxide for $10 \mathrm{~min}$ at $37^{\circ} \mathrm{C}$ for endogenous peroxidase blocking, washed twice with $\mathrm{PBS}$ ( $\mathrm{pH} \mathrm{7.4;5} \mathrm{min}$; room temperature), and then 
blocked with normal goat serum for $20 \mathrm{~min}$ at room temperature (cat. no. ab7481; Abcam). Incubation with anti-BAP31 (cat. no. ab237485; Abcam; 1:1,000) was performed overnight at $4^{\circ} \mathrm{C}$. Sections were then incubated with the secondary antibody for $1 \mathrm{~h}$ at room temperature (cat. no. ZB-2301; 1:5,000; OriGene Technologies, Inc.). Between each step, the sections were washed three times with PBS ( $\mathrm{pH} 7.4)$. Coloration with 3,3-diaminobenzidin $(1 \mathrm{mg} / \mathrm{ml})$ was performed in the dark for $5 \mathrm{~min}$ at room temperature, followed by counterstaining with hematoxylin $(8 \mathrm{mg} / \mathrm{ml})$ for $5 \mathrm{~min}$ at room temperature. Between each staining, the sections were washed three times with tap water. BAP31-positive ovarian cancer tissue served as a positive control and tissue incubated with $10 \%$ pre-immune rabbit serum overnight at $4^{\circ} \mathrm{C}$ as a negative control. The stained slides were examined using an Olympus DP70 light microscope (Olympus Corporation; magnification, x20).

Cell culture. Human ovarian normal epithelial cell line IOSE80 and five ovarian cancer cell lines (A2780, Hey-T30, COC1, SKOV3 and OVCAR3) were obtained from the BeNa Culture Collection; Beijing Beina Chuanglian Biotechnology Research Institute. Mycoplasma testing was performed for all cell lines used, and cell lines were tested and identified using short tandem repeats. All cell lines were cultured in DMEM supplemented with 10\% FBS (ProSpec-Tany TechnoGene, Ltd.) and $100 \mathrm{mg} / \mathrm{ml}$ penicillin/streptomycin (ProSpec-Tany TechnoGene, Ltd.). Cells were cultured in a humidified $5 \% \mathrm{CO}_{2}$ atmosphere at $37^{\circ} \mathrm{C}$.

Cell transfection. BCAP31 shRNA lentiviral transduction particles and shRNA negative control (shCtrl) transduction particles were purchased from Sigma-Aldrich; Merck KGaA. The sequences of shRNA vectors (pLKO.1; Sigma-Aldrich; Merck KGaA) that targeted BCAP31 were 5'-CCGGCATGG ACAAGAAGGAAGAGTACTCGAGTACTCTTCCTTCTTG TCCATGTTTTTTG-3' [shBCAP31-1, The RNAi Consortium (TRC) no.TRCN0000179092] and5'-CCGGCCTATGGCAAC ACCTTCTTTGCTCGAGCAAAGAAGGTGTTGCCATAG GTTTTTG-3' (shBCAP31-2, TRC no. TRCN0000242709). The vector shRNA negative control (shCtrl) was purchased form Sigma-Aldrich (MISSION ${ }^{\circledR}$ SHC016-1EA; Merck KGaA) and contained shRNA insert that does not target any known genes from any species. The BCAP31 shRNA lentiviral plasmid or shRNA negative control plasmid and pPACK Packaging Plasmid mix (cat. no. K497500; Invitrogen; Thermo Fisher Scientific, Inc.) were co-transfected into the healthy digested $293 \mathrm{~T}$ cells (Type Culture Collection of Chinese Academy of Sciences, Shanghai, China) using Lipofectamine ${ }^{\circledR} 3000$ (cat. no. L3000-015; Invitrogen; Thermo Fisher Scientific, Inc.) at $37^{\circ} \mathrm{C}$. The medium was replaced at $8 \mathrm{~h}$ and cultivation was continued until $48 \mathrm{~h}$. The supernatant of each culture was collected for centrifugation at $4,000 \mathrm{x} \mathrm{g}$ and $4^{\circ} \mathrm{C}$ for $10 \mathrm{~min}$ to remove cell debris, followed by further filtration with $\mathrm{A}$ filter $(0.45 \mu \mathrm{m})$ to obtain concentrated lentivirus solution. The virus suspension was added to the A2780 and Hey-T30 cells medium for transfection at a concentration of $1.5 \times 10^{7}$ international units (IU). The cells were harvested at 2 days post-transduction for proliferation, migration and invasion assays, or at 4 days post-transduction for reverse transcription-quantitative (RT-q) PCR or western blot analysis.
BCAP31 small interfering (si)RNA (siRNA IID. 138059), SNAI1 siRNA (siRNA IID. 107915), SNAI2 siRNA (siRNA IID. 106954), ZEB1 siRNA (siRNA IID. 109651), ZEB2 siRNA (siRNA IID. 108632), TWIST1 siRNA (siRNA ID. 106119), TWIST2 siRNA (siRNA IID. 114998) and control siRNA (siCtrl; cat. no. AM4641) were purchased from Invitrogen,(silencer ${ }^{\circledR}$, Thermo Fisher Scientific, Inc.). Then, $50 \mathrm{nmol} / 1$ siRNA sequences and recombinant lentivirus (BCAP31-shRNA1, BCAP31-shRNA 2 and shRNA-NC) were transfected into A2780 cells using the Lipofectamine ${ }^{\circledR} 3000$ reagent (cat. no. L3000-015; Invitrogen; Thermo Fisher Scientific, Inc.), shBCAP cell lines and siRNA cell lines were obtained after $48 \mathrm{~h}$.

RNA extracted from A2780 was reverse transcribed to cDNA using PrimeScript ${ }^{\mathrm{TM}}$ RT Master Mix (Perfect Real Time; cat. no. RR036A; Takara Bio, Inc.) as follows: $25^{\circ} \mathrm{C}$ for $2 \mathrm{~min}, 42^{\circ} \mathrm{C}$ for $50 \mathrm{~min}$ and $75^{\circ} \mathrm{C}$ for $15 \mathrm{~min}$. PrimeSTAR HS DNA Polymerase (cat. no. R010B; Takara Bio, Inc.) was used for PCR reaction with the primers listed in Table I. TWIST1 cDNA was cloned into the pcDNA3.1 vector (Generay Biotech Co., Ltd.) to construct the expression vector pdTWIST. The successfully constructed expression vector pdTWIST $(5 \mu \mathrm{g} / \mu \mathrm{l})$ was transfected into shBCAP31 cells, and a shBCAP31 + TWIST1 cell line was obtained. Subsequent in vitro assays were performed 3 days post-transfection. The empty pcDNA3.1 was transfected into A2780 cells to obtain an OE Ctrl cell line.

RNA extraction and RT- $q P C R)$. RNA was extracted from the cell lines (IOSE80, A2780, Hey-T30, COC1,SKOV3, OVCAR3, shCtrl, shBCAP31-1, shBCAP31-2, shBCAP31 + OE WTIST1, OE Ctrl, OE TWIST1, siCtrl, siBCAP31 and siTWIST1) using QIAzol lysis reagent (Qiagen $\mathrm{GmbH}$ ) and purified with a RNeasy mini kit (Qiagen $\mathrm{GmbH}$ ). RNA was treated with DNase I (New England BioLabs, Inc.) to remove genomic DNA. RNA quality and quantity were analyzed using a NanoDrop spectrophotometer (NanoDrop program 1000 version 3.8.2; NanoDrop Technologies; Thermo Fisher Scientific, Inc.) and Bioanalyzer (Agilent, Technologies, Inc.). For RT-qPCR, PrimeScript ${ }^{\mathrm{TM}}$ RT Master Mix (Perfect Real Time; cat. no. RR036A; Takara Bio, Inc.) was used to reverse transcribe $1,000 \mathrm{ng}$ total RNA to cDNA in a final volume of $20 \mu \mathrm{l}$. RT was performed as follows: $25^{\circ} \mathrm{C}$ for $2 \mathrm{~min}, 42^{\circ} \mathrm{C}$ for $50 \mathrm{~min}$ and $75^{\circ} \mathrm{C}$ for $15 \mathrm{~min}$. qPCR was performed using SYBR Select Master mix (cat. no. 4472908; Applied Biosystems; Thermo Fisher Scientific, Inc.). The primers used for BCAP31, cadherin (CDH)1, CDH2, vimentin (VIM), actin $\alpha 2$ (Acta2), SNAI1, SNAI2, ZEB1, ZEB2, TWIST1, TWIST2 and GAPDH are listed in Table I. QuantStudio ${ }^{\mathrm{TM}} 6$ Flex Real-Time PCR system (Thermo Fisher Scientific, Inc.) was used to collect RT-qPCR data. The RT-qPCR reaction included an initial denaturation step at $95^{\circ} \mathrm{C}$ for $10 \mathrm{~min}$, followed by 40 cycles at $93^{\circ} \mathrm{C}$ for $15 \mathrm{sec}$ and $60^{\circ} \mathrm{C}$ for $1 \mathrm{~min}$. Each sample was carried out in triplicate, and relative expression was calculated and normalized using the $2^{-\Delta \Delta \mathrm{Cq}}$ method (44) relative to $\beta$-actin.

Transcriptome sequencing. RNA was extracted from shCtrl, shBCAP31-1 and shBCAP31-2 cells using QIAzol lysis reagent (Qiagen, $\mathrm{GmbH}$ ) and subsequently purified with a RNeasy mini kit (Qiagen, GmbH). Purified RNA was digested 
Table I. Primer sequences used for reverse transcription-quantitative PCR.

\begin{tabular}{|c|c|c|}
\hline Gene name & Forward, $5^{\prime} \rightarrow 3^{\prime}$ & Reverse, $5^{\prime} \rightarrow 3^{\prime}$ \\
\hline BAP31 & GCCACСТTCСТCTACGCAG & GCCATAGGTCACTACCAACTC \\
\hline CDH1 & TAACCGATCAGAATGAC & TTTGTCAGGGACTCAGG \\
\hline $\mathrm{CDH} 2$ & ATTGTGGGTG CGGGGCTTGG & GGGTGTGGGGCTGCAGATCG \\
\hline VIM & AGTCCACTGAGTACCGGAGAC & CAT TTCACGCATCTGGCGTTC \\
\hline Acta 2 & GGGACATCAAGGAGAAACTGTGT & TCTCTGGGCAGCGGAAAC \\
\hline SNAI1 & TCTGGTTCTGTGTCCTCTGC & TTCCCAGTGAGTCTGTCAGC \\
\hline SNAI2 & TGTCATACCACAACCAGAGA & CTTGGAGGAGGTGTCAGAT \\
\hline ZEB1 & AGACTATTCTGATTCCCCAAGTG & CCTTCTGAGCTAGTGTCTTGTC \\
\hline ZEB2 & AATGCACAGAGTGTGGCAAGGC & CTGCTGATGTGCGAACTGTAGG \\
\hline TWIST1 & GTCCGCAGTCTTACGAGGAG & CCAGCTTGAGGGTCTGAATC \\
\hline TWIST2 & TGGACCAAGGCTCTCAGAACA & ACAGGAGTATGCGGGCAAGA \\
\hline TWIST1 $*$ & CCaagcttAACTCCCAGACACCTCGCGGG & GCggatccTTCTCTAAАTTTTTTATATTTA \\
\hline GAPDH & ATCACTGCCACCCAGAAGAC & TTTCTAGACGGCAGGTCAGG \\
\hline
\end{tabular}

BAP31, B cell receptor associated protein 31; CDH1, cadherin 1; VIM, vimentin; Acta2, actin $\alpha 2$; SNAI, snail family; ZEB, zinc finger E-box binding homeobox; TWIST1*, TWIST1 cDNA used to cloned into the pcDNA3.1 vector. Lowercase letters represent restriction sites.

with DNase I (New England Biolabs, Inc.) to remove residual genomic DNA. RNA quality and quantity were analyzed using a NanoDrop and Bioanalyzer respectively. RNA-seq library preparation and sequencing were performed at the Beijing GeneX Health Co., Ltd. Libraries (300 bp) were constructed using a NuGen ${ }^{\circledR}$ Ovation human FFPE RNA-seq multiplex system kit (cat. no. 1707160; Ovation ${ }^{\circledR}$ Ultralow System V2; Tecan Group., Ltd.). Directional mRNA-seq was conducted using the HiSeq 2000 system (Illumina, Inc.) using the single-read 100 cycles option. The nucleotide length to be sequenced was $300 \mathrm{bp}$, and double-end pyrosequencing was performed with the read lengths of $150 \mathrm{bp}$ for each end. The effective concentration of each library was quantified accurately by qPCR to ensure the quality of the library, and the library loading concentration was $2.2 \mathrm{pM}$. The resulting raw data were transformed into sequenced reads by base calling. The poor quality reads were filtered by fastq-tools v0.8 (homes.cs.washington.edu/ dcjones/fastq-tools/); clean reads were mapped to the reference genome by using HISAT2 (ccb.jhu.edu/software/hisat2). DEGseq version 1.36.1was used to analyze differential expression genes (45). The differential expression genes were determined by $\log _{2}$ fold change $>2$ and adjusted $\mathrm{P}$-value $<0.05$.

Nuclear and cytoplasmic fractionation of proteins. A nuclear and cytoplasmic protein extraction kit (Beyotime Institute of Biotechnology) was used to extract cytosolic and nuclear proteins from shCtrl, shBCAP31 and shBCAP31 + OE TWIST1 cells according to manufacturer's protocol. All isolated fractions were analyzed by western blotting.

Western blotting. Cell lines (IOSE80, A2780, Hey-T30, COC1, SKOV3, OVCAR3, shCtrl, shBCAP31-1, shBCAP31-2, siCtrl, shBCAP31 + OE TWIST, siBCAP31 and siTWIST1) were harvested and processed in lysis buffer [50 mM Tris- $\mathrm{HCl}$ (pH, 7.4), $150 \mathrm{mM} \mathrm{NaCl}, 1 \%$ TritonX-100, 0.2\% SDS, $10 \mathrm{mM}$ $\beta$-mercaptoethanol and 5\% glycerol] on ice before a BCA protein assay kit (Nanjing KeyGen Biotech Co., Ltd.) was utilized to quantify protein concentrations. Cell extracts were boiled for $5 \mathrm{~min}$ in loading buffer before equal amounts of protein $(6-10 \mu \mathrm{g})$ were separated via $10 \%$ SDS-PAGE. Separated protein bands were then transferred onto polyvinylidene fluoride membranes. The membranes were blocked in 5\% skimmed milk powder in Tris-buffered saline with $0.1 \%$ Tween-20 (TBST) for $1 \mathrm{~h}$ at $37^{\circ} \mathrm{C}$ and subsequently incubated overnight at $4^{\circ} \mathrm{C}$ with primary antibodies against BAP31 (cat. no. ab237485; 1:3,000), N-cadherin (cat. no. ab76057; $1: 1,000)$, E-cadherin (cat. no. ab76055; 1:1,000), SNAI1 (cat. no. ab216347; 1:1,000), SNAI2 (cat. no. ab27568; 1:1,000), ZEB1 (cat. no. ab203829; 1:500), ZEB2 (cat. no. ab138222; 1:1,000), Twist1 (cat. no. ab175430; 1:1,500), Twist2 (cat. no. ab66031; 1:2,000), VIM (cat. no. ab137321; $1: 2,000), \alpha$-smooth muscle actin ( $\alpha$-SMA; cat. no. ab32575; 1:3,000), $\beta$-tubulin (cat. no. ab210797; 1:1,000), Lamin B1 (cat. no. ab133741; 1:2,000) and $\beta$-actin (cat. no. ab115777; 1:1,000). After washing with TBST three times, the membrane was incubated with a HRP-conjugated goat anti-rabbit secondary antibody (cat. no. ab7090; 1:10,000) at room temperature for $2 \mathrm{~h}$. ECL Substrate kit (cat. no. 36222ES60; Shanghai Yeasen Biotechnology Co. Ltd.) was used to visualize the bands on the membrane. The primary and secondary antibodies were purchased from Abcam. All experiments were independently repeated $\geq$ three times.

In vitro proliferation, migration and invasion assays. Cell lines were used to detect the ability of proliferation, migration and invasion, including shCtrl, shBCAP31-1, shBCAP31-1 and shBCAP31 + OE TWIST1 cell lines.

Cell viability. The viability of cells was examined using Cell Counting Kit-8 (CCK-8) assays (Beijing Solarbio Science $\&$ Technology Co., Ltd.). Cells were seeded at a density 
of 1,000 cells/well in a 96-well plate and were cultured in humidified $5 \% \mathrm{CO}_{2}$ atmosphere at $37^{\circ} \mathrm{C}$ for 24,48 or $72 \mathrm{~h}$. Before detection, $10 \mu \mathrm{l}$ CCK- 8 reagent was added into each well and incubated at $37^{\circ} \mathrm{C}$ for an additional $1.5 \mathrm{~h}$ at $37^{\circ} \mathrm{C}$. The optical density value was measured at $450 \mathrm{~nm}$ using a microplate reader (Multimode Reader; PerkinElmer, Inc.). Cell numbers were analyzed and a growth curve was drawn. The cell count fold-change was calculated as follows: Cell count fold-change $\mathrm{e}_{(\mathrm{t})}=\mathrm{OD}_{(\mathrm{t})} / \mathrm{OD}_{(\mathrm{t}-24)}$. Each experiment was repeated three times.

Cell migration and invasion assays. Cell migration and invasion assays were performed in $6.5-\mathrm{mm}$ Transwell inserts (pore size, $8.0 \mu \mathrm{m}$; cat. no. 3422; Corning, Inc.). Cells $\left(2 \times 10^{5}\right)$ suspended in $100 \mu \mathrm{l}$ serum-free DMEM were added into the upper chamber, whilst the lower chamber was filled with complete DMEM with $10 \%$ FBS. For migration assay, cells were allowed to migrate at $37^{\circ} \mathrm{C}$ for $18 \mathrm{~h}$. For the invasion assay, Transwell inserts were first coated at $37^{\circ} \mathrm{C}$ with $20 \mu \mathrm{l}$ Matrigel (BD Biosciences) mixed with DMEM in a ratio of 1:4 for $30 \mathrm{~min}$ and cells were allowed to invade for $24 \mathrm{~h}$ at $37^{\circ} \mathrm{C}$. After removing the non-migratory cells, the membranes were fixed in $20 \%$ methanol at room temperature for $10 \mathrm{~min}$ and stained with $100 \mathrm{ng} / \mathrm{ml} \mathrm{4,6-diamidino-2-phenylindole} \mathrm{dihy-}$ drochloride (DAPI) solution (Thermo Fisher Scientific, Inc.) at room temperature for $15 \mathrm{~min}$. Microscopy was performed on a Nikon E800 microscope with a 100x 1.40 Plan-Apo objective lens and five fields of view per chamber. Migratory and invasive cells were imaged using Nikon eclipse Ti2 fluorescent microscope, before cell migration and invasion were quantified using ImageJ software (1.38, National Institutes of Health). Each sample was assayed in triplicate.

Co-immunoprecipitation (Co-IP) assay. Cells were harvested in $1 \%$ NP40 lysis buffer [150 mM NaCl, $50 \mathrm{mM}$ Tris- $\mathrm{HCl}$ ( $\mathrm{pH} 7.4$ ) and $1 \%$ Nonidet $\mathrm{P}-40]$ containing protease and phosphatase inhibitors (Sangon Biotech Co., Ltd.) and the supernatant was removed after centrifugation at 1,000 $\mathrm{x} g$ for $1 \mathrm{~min}$ at $4^{\circ} \mathrm{C}$. The binding of BAP31 (cat. no. ab237485,1:1,000, Abcam), E-cadherin (cat. no. ab76055; 1:100, Abcam), N-cadherin (cat. no. ab76057; 1:100, Abcam) or Twist1 (cat. no. ab175430; 1:500, Abcam) antibody to protein G agarose was performed using a Protein G Immunoprecipitation kit (cat. no. 11719386001; Sigma-Aldrich; Merck KGaA). The protein A/G agarose slurry $(20 \mu \mathrm{l})$ was washed twice with $200 \mu \mathrm{l}$ PBS buffer and then incubated with $100 \mu \mathrm{l}$ antibody in PBS $\left(10 \mu \mathrm{l}\right.$ antibody $\left.+85 \mu 1 \mathrm{H}_{2} \mathrm{O}+5 \mu \mathrm{l} 20 \mathrm{X} \mathrm{PBS}\right)$ at $25^{\circ} \mathrm{C}$ for $30 \mathrm{~min}$ on a mixer In parallel, $100 \mu 1$ rabbit serum (cat. no. ab7487, Abcam) or anti-rabbit IgG peroxidase secondary antibody (cat. no. ab6721, Abcam) with $2 \mu \mathrm{g} / \mu \mathrm{lgG}$ was prepared as the negative control. The immunoprecipitated products (isolated by centrifugation at $2,000 \mathrm{x}$ g for $1 \mathrm{~min}$ at $4^{\circ} \mathrm{C}$ ) were washed with washing buffer five times and eluted with $2 \mathrm{X}$ Laemmli buffer at $100^{\circ} \mathrm{C}$ for $10 \mathrm{~min}$. Three independent experiments were performed. Finally, the eluate and flow-through were separated by $10 \%$ SDS-PAGE and analyzed by western blotting.

Statistical analysis. All statistical analyses were performed using the SPSS 18.0 statistical software package (SPSS, Inc.). All values are presented as the mean \pm standard deviation.
All data were statistically analyzed using one-way analysis of variance (ANOVA) with a Bonferroni correction. The significance of the differences between groups were determined by paired Student's t-test (for comparison between two groups) or one way ANOVA followed by LSD test. The experiments were performed in triplicate. Data are presented as the mean \pm SD. $\mathrm{P}<0.05$ was considered to indicate a statistically significant difference.

\section{Results}

BAP31 expression is upregulated in ovarian cancer cells. The expression of BAP31 in the human ovarian epithelial cell line IOSE80 and five ovarian cancer cell lines, including A2780 and Hey-T30 cells, was measured. The results showed that the expression of BAP31 in the ovarian cancer cell lines was markedly higher compared with that in IOSE80 cells on both mRNA and protein levels (Fig. S1). The protein expression of BAP31 was observed to be upregulated in ovarian cancer cells, notably in A2780 (Fig. 1A and B), whilst the mRNA expression of BCAP31 in the two ovarian cancer cell lines (A2780 and Hey-T30) tested was significantly higher compared with that observed in IOSE80 cells (Fig. 1B), particularly for A2780 cells, in which expression levels were nine times higher than those in IOSE80 cells. An analysis on the relative expression of BAP31 in cancer and paracancerous tissue from patients with ovarian cancer was also performed. The results showed that BAP31 was highly expressed in ovarian cancer tissues compared with that in the surrounding paracancerous tissues (Fig. 1C).

Knockdown of BAP31 inhibits the viability, migration and invasion of ovarian cancer cells. Two shRNA lentiviral vectors specifically targeting BCAP31 were constructed, following which A2780 cells were transfected after viral packaging to obtain the shBCAP31-1 and shBCAP31-2 cell lines. The protein and mRNA expression of BCAP31 was markedly reduced in the two shBCAP31 groups (Fig. 2A and B), where BCAP31 mRNA expression in the two shBAP31 groups was significantly lower compared with that observed in the shCtrl group (Fig. 2B) according to RT-qPCR analysis. Further examination revealed that the cell viability, migration and invasion of the shBCAP31 cell lines were all markedly inhibited. The viability of the two shBCAP31 A2780 cell lines was significantly reduced compared with that observed in the shCtrl cells (Fig. 2C and D), whilst the migratory and invasive abilities were significantly reduced in the two shBCAP31 A2780 cell lines compared with that in the shCtrl cells (Fig. 2E and F). Similar trends were also observed in Hey-T30 cells transfected with shBCAP31-1 and shBCAP31-2 (Fig. S2).

Effects of BAP31 knockdown on the expression of E-cadherin and $N$-cadherin. To explore the specific underlying mechanism of BAP31 on the proliferation, migration and invasion of A2780 cells, the differentially expressed genes were detected by RNA sequencing in the shBCAP31-1, shBCAP31-2 and shCtrl groups. Among the 10 most differentially expressed genes found in the two shBAP31 cell groups, E-cadherin and $\mathrm{N}$-cadherin were identified (Fig. 3A; Table SI), which are genes that have important reported roles in EMT (21). Further 

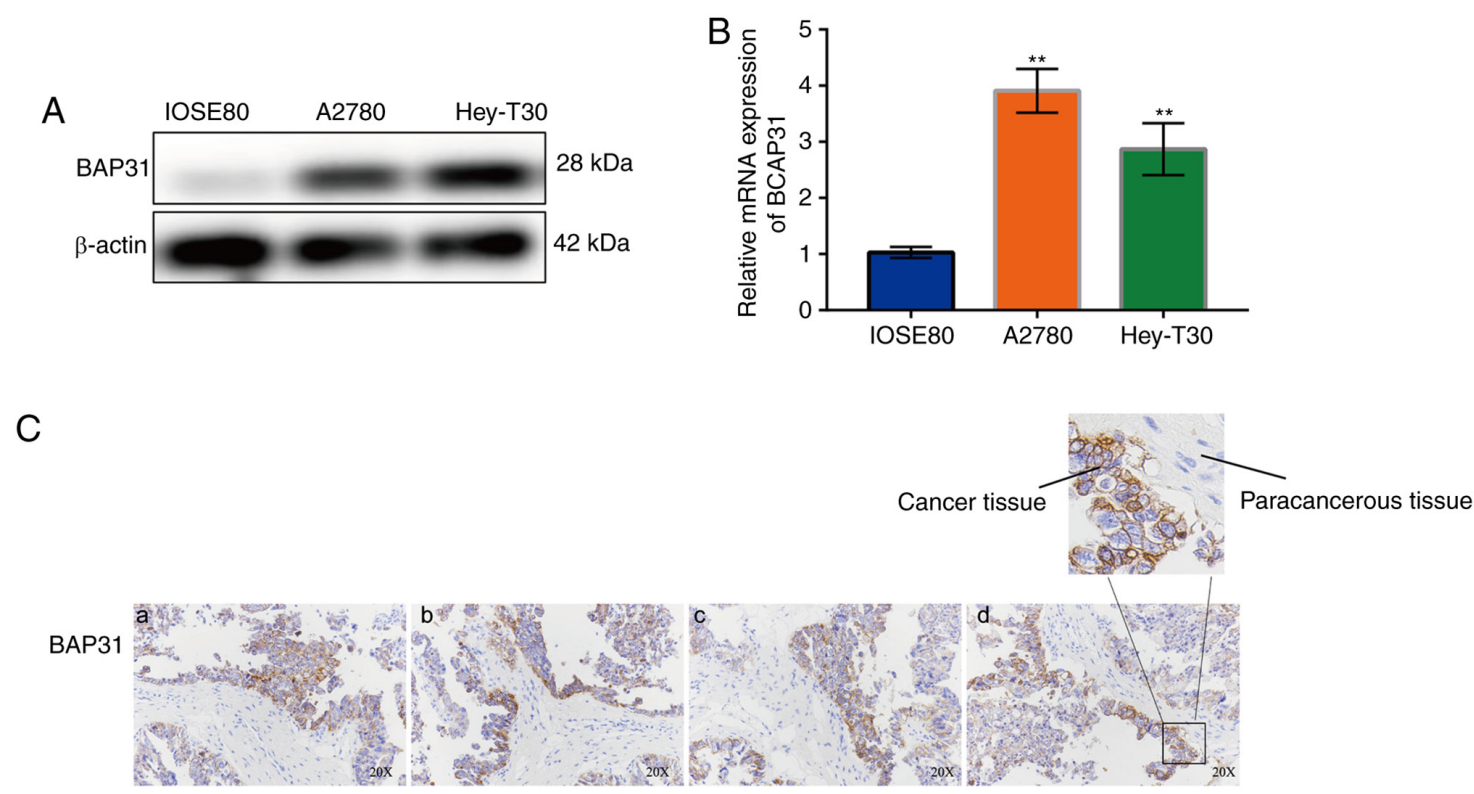

Figure 1. BAP31 expression is upregulated in ovarian cancer cells. (A) Protein and (B) mRNA expression of BAP31 is higher in the two ovarian cancer cell lines A2780 and Hey-T30 cells compared with that in IOSE80 cells. BAP31 mRNA and protein expression were assessed by reverse transcription-quantitative PCR and western blotting, respectively ( $\beta$-actin was the reference gene, $n=3)(C)$ Immunohistochemistry staining for BAP31 in cancer and adjacent tissues from patients with ovarian cancer. a-d, four independent samples. The stained slides were examined using an Olympus DP70 light microscope (magnification, $\mathrm{x} 20) .{ }^{* *} \mathrm{P}<0.01$ vs. IOSE80. BAP31, B cell receptor-associated protein 31.
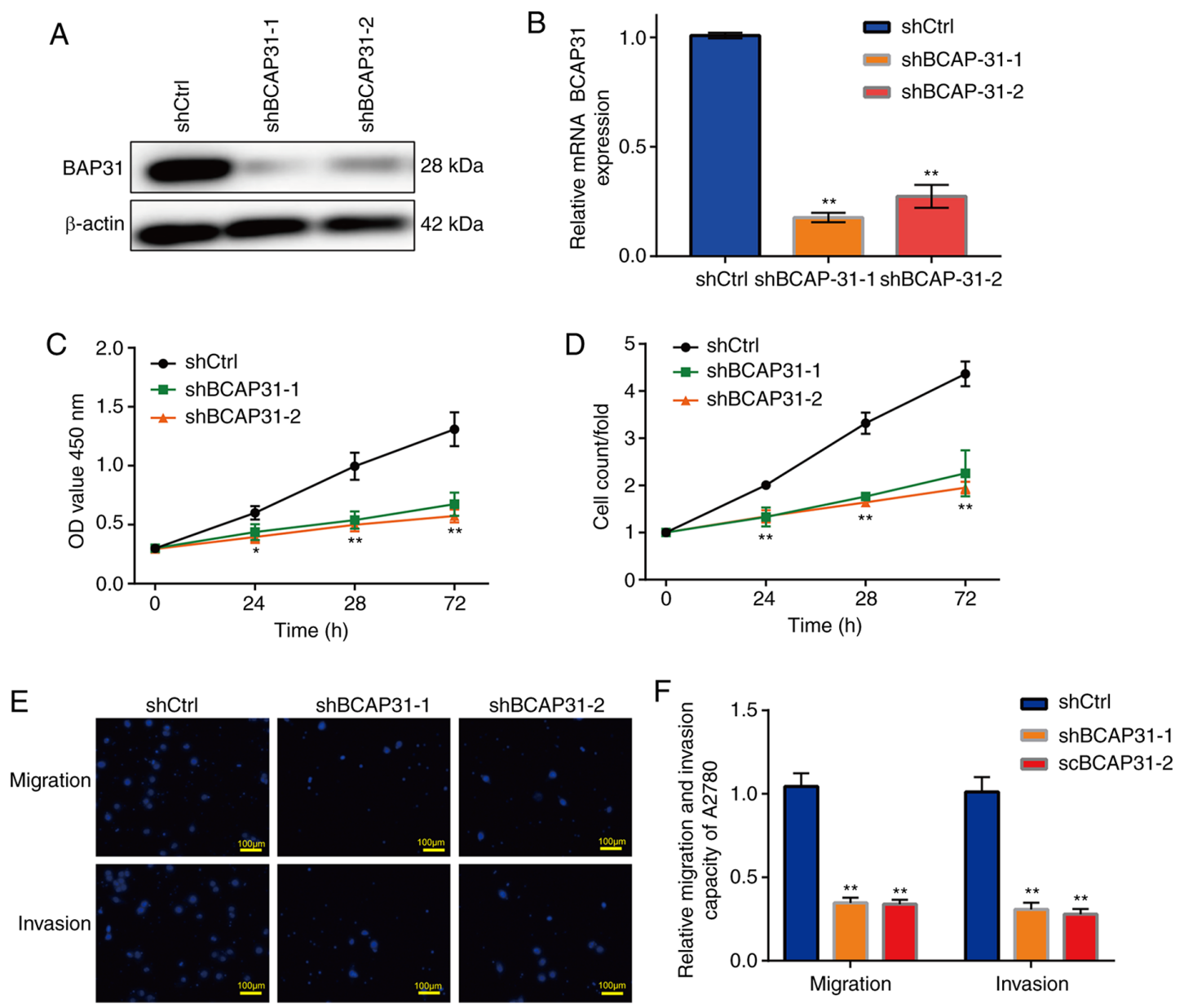

Figure 2. Knockdown of BCAP31 inhibits the proliferation, migration and invasion of A2780 ovarian cancer cells. (A) Protein and (B) mRNA expression of BAP31 is downregulated in A2780 cells transfected with shBCAP31-1 and shBCAP31-2. (C) Growth curve derived from the OD values. (D) Cell count fold-change among shCtrl, shBCAP31-1 and shBCAP31-2. (E) Representative Transwell assay images of migratory and invasive shCtrl, shBCAP31-1 and shBCAP31-2 A2780 cells. (F) Relative migratory and invasive activities of shCtrl, shBCAP31-1 and shBCAP31-2 A2780 cells. ${ }^{*} \mathrm{P}<0.05,{ }^{* *} \mathrm{P}<0.01$ vs. shCtrl. BAP31 or BCAP31, B cell receptor-associated protein 31; sh, short hairpin RNA; OD, optical density; Ctrl, control. 
A

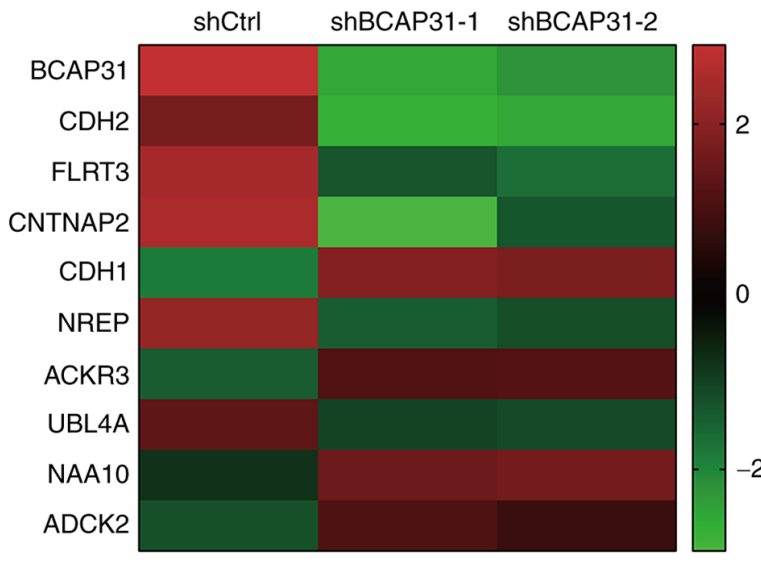

C

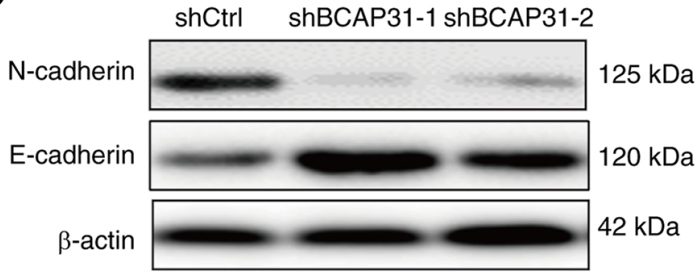

B

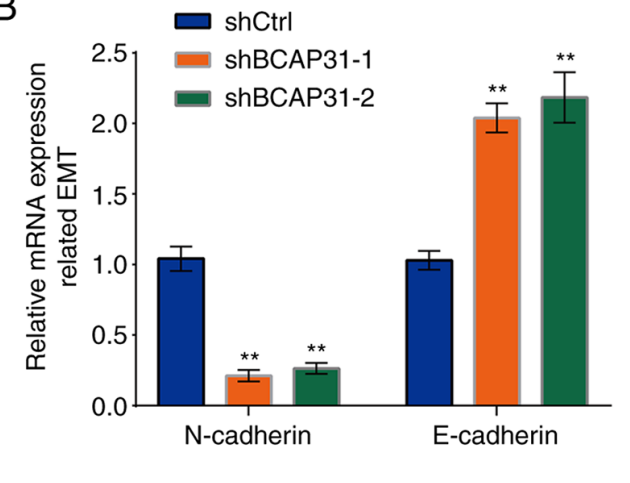

$\mathrm{D}$

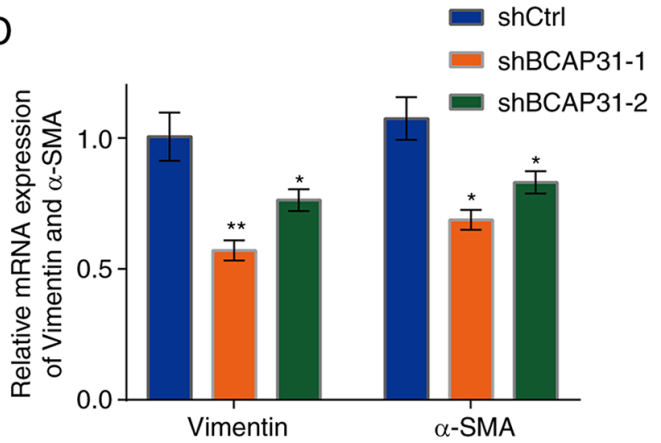

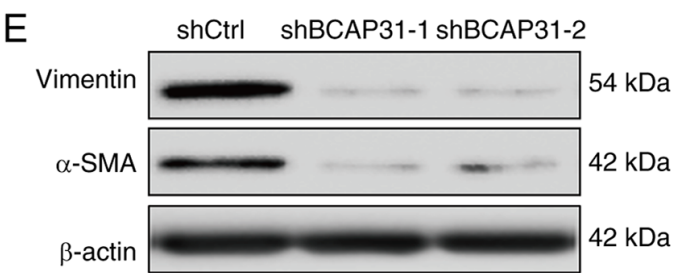

Figure 3. BAP31 regulates the expression of EMT proteins. (A) Top 10 differentially expressed genes in shCtrl, shBCAP31-1 and shBCAP31-2 A2780 cells. (B) mRNA and (C) protein expression of E-cadherin and N-cadherin. (D) mRNA and (E) protein expression of EMT-related genes vimentin and $\alpha$-SMA, in shCtrl, shBCAP31-1 and shBCAP31-2 A2780 cells. ${ }^{*} \mathrm{P}<0.05$ and ${ }^{* *} \mathrm{P}<0.01$ vs. shCtrl. BAP31 or BCAP31, B cell receptor-associated protein 31; EMT, epithelial-to-mesenchymal transition; sh, short hairpin RNA; $\alpha$-SMA, $\alpha$-smooth muscle actin; Ctrl, control; CDH, cadherin; FLRT3, fibronectin leucine-rich transmembrane protein 3; CNTNAP2, contactin-associated protein 2; NREP, neuronal regeneration-related protein; ACKR3, atypical chemokine receptor 3; UBL4A, ubiquitin-like 4A; NAA10, N- $\alpha$-acetyltransferase 10, NatA catalytic subunit; ADCK2, AarF domain containing kinase 2.

verification revealed that the mRNA (Fig. 3B) and protein expression (Fig. 3C) levels of E-cadherin were markedly upregulated in the two shBCAP31 cell lines, whereas N-cadherin expression was markedly downregulated, compared with those in the shCtrl cells. The expression levels of vimentin and $\alpha$-SMA, both of which are associated with EMT (46), were next detected. The mRNA (Fig. 3D) and protein (Fig. 3E) levels were also markedly downregulated following transfection with shBCAP31-1 and shBCAP31-2 compared with those in shCtrl cells. This suggests that BAP31 may potentiate the proliferation, migration and invasion of ovarian cancer cells by regulating EMT.

$B A P 31$ regulates the expression of $E$-cadherin and $N$-cadherin on a transcriptional level. It was found that the knockdown of BAP31 affected the relative mRNA expression levels of E-cadherin and N-cadherin (Fig. 3). No previous studies have described the DNA-binding domain of BAP31, and there was no interaction found between BAP31 and E-cadherin or $\mathrm{N}$-cadherin using Co-IP detection (Fig. 4A). Previous studies have reported that the TFs, including SNAI1, SNAI2, ZEB1,
ZEB2, TWIST1 and TWIST2, can simultaneously regulate the expression of E-cadherin and N-cadherin (47). After the respective siRNAs were used to knock down the expression levels of these TFs aforementioned in A2780 cells, the mRNA expression levels of $\mathrm{N}$-cadherin were downregulated by differing degrees in all siRNAs tested compared with those in cells transfected with siCtrl (Fig. S3). By contrast, the mRNA expression levels of E-cadherin were increased by differing degrees in all siRNAs tested compared with those in cells transfected with siCtrl, except for those transfected with siZEB1 (Fig. S3). The knockdown of BAP31 expression did not affect the mRNA or the protein expression levels of these TFs (Fig. 4B and C), but altered the nuclear distribution of TWIST1, specifically markedly reducing its nuclear aggregation (Fig. 4D). An interaction was observed between BAP31 and TWIST1 (Fig. 4E). siRNAs were then used to knock down the expression levels of BAP31 and TWIST1, following which the mRNA and protein expression levels of E-cadherin and $\mathrm{N}$-cadherin in the TWIST1 siRNA group exhibited comparable expression as that seen in the siBCAP31 cell line (Fig. 4F and G). 
A

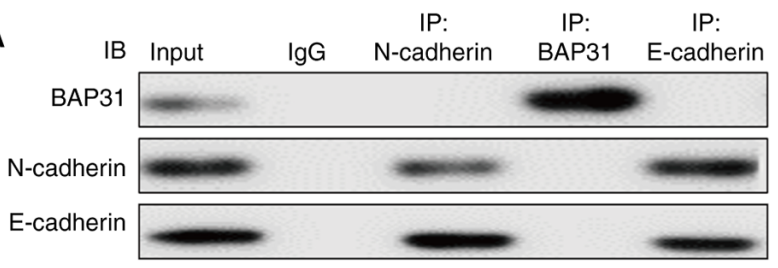

C

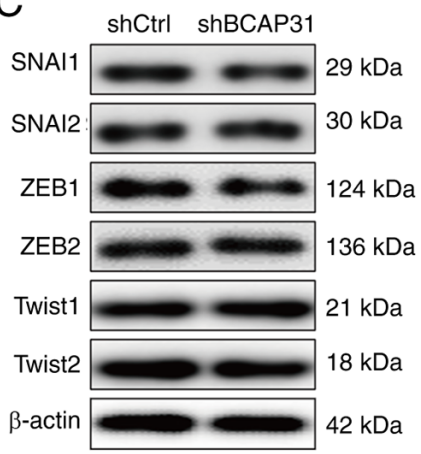

$\mathrm{D}$

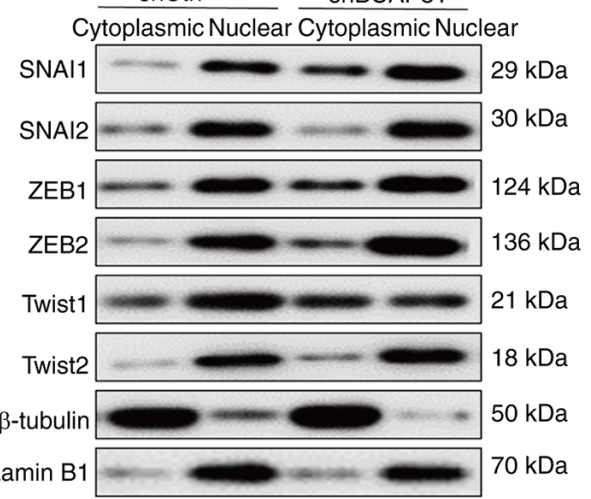

G
B

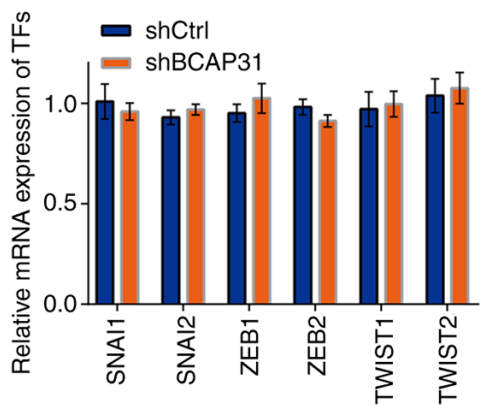

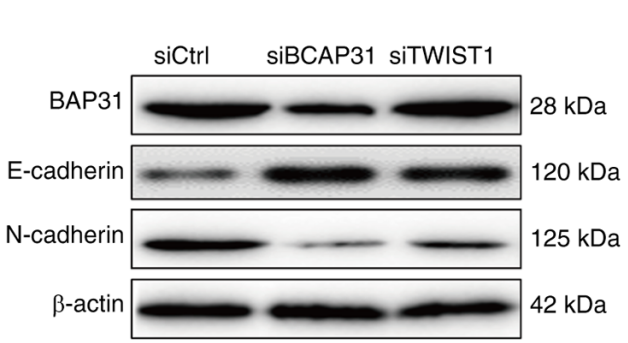

Figure 4. BAP31 regulates the expression of E-cadherin and N-cadherin at the transcriptional level through TWIST1. (A) Interaction between BAP31 and E-cadherin or N-cadherin in A2780 shCtrl cells. (B) mRNA and (C) protein expression of TFs that may regulate E-cadherin and N-cadherin expression in shCtrl and shBCAP31 A2780 cells. (D) Protein expression of TFs in the cytoplasmic and nuclear fractions of shCtrl and shBAP31 A2780 cells. (E) Interaction between BAP31 and TWIST1 in A2780 shCtrl cells. (F) mRNA and (G) protein expression of N-cadherin and E-cadherin in A2780 cells transfected with siCtrl, siBCAP31 and siTWIST1. ${ }^{* *} \mathrm{P}<0.01$ vs. siCtrl BAP31 or BCAP31, B cell receptor-associated protein 31; sh, short hairpin RNA; TF, transcription factor; si, small interfering RNA; Ctrl, control; SNAI, snail family; IB, immunoblot; IP, immunoprecipitation; ZEB, zinc finger E-box-binding homeobox 1; $\mathrm{CDH}$, cadherin.

Overexpression of TWIST1 in the shBAP31 cell line can restore cell functions and protein expression. The expression vector pdTWIST1 (TWIST1 cDNA was cloned into the pcDNA3.1 vector) was transfected into shBCAP31 A2780 cells to obtain the shBCAP31 + OE TWIST1 A2780 cell line, before the mRNA expression of BCAP31 and TWIST1 in the A2780 cells following eight different transfection protocols (shCtrl, siCtrl, OE Ctrl, shBCAP31, siBCAP31, siTWIST1, OE TWIST1 and shBCAP31 + OE TWIST1) were analyzed by RT-qPCR. The mRNA expression of BCAP31 was decreased in the shBCAP31 and shBCAP31 + OE TWIST1 groups compared with shCtrl group, and which in siBCAP31 group was decreased compared with siCtrl group. Whilst the mRNA expression of TWIST1 was decreased in siTWIST1 group compared with siCtrl and increased in the OE TWIST1 and shBCAP31 + OE TWIST1 groups compared with shCtrl group (Fig. S4). After TWIST1 was overexpressed in the shBCAP31 A2780 cell line (shBCAP31 + OE TWIST1), the nuclear and cytoplasmic distribution of TWIST1 was comparable with that found in the shBCAP31 cell line, whilst the protein levels in the nucleus was markedly higher compared with those in the shBCAP31 group (Fig. 5A). Cell viability (Fig. 5B), migration and invasion (Fig. 5C and D) in the shBCAP31 + OE TWIST1 group were all increased compared with those in the shBCAP31 group, similar to the level observed in the shCtrl group. Subsequently, the mRNA and protein expression of $\mathrm{N}$-cadherin and E-cadherin was explored, where it was found that the mRNA (Fig. 5E) and protein (Fig. 5F) expression levels of N-cadherin in the shBCAP31 + OE TWIST1 group were markedly higher compared with those in the shBCAP31 group and comparable with those in the shCtrl group. By contrast, E-cadherin expression in the shBCAP31 + OE TWIST1 group exhibited the opposite trend.

\section{Discussion}

BAP31 is a B cell receptor protein that is an integrated $28-\mathrm{KDa}$ multimer and is evolutionarily conserved and ubiquitously expressed (8). Studies have previously shown that in addition to participating in the activation of B cell receptors, BAP31 can 
A

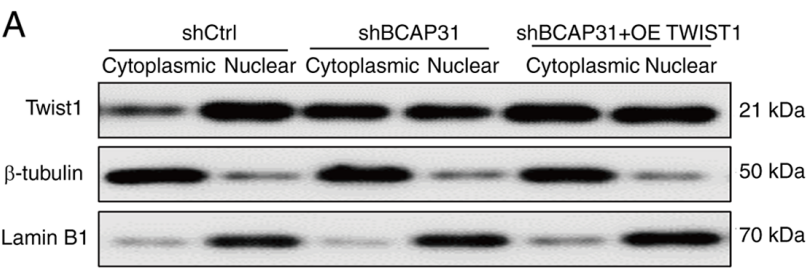

B

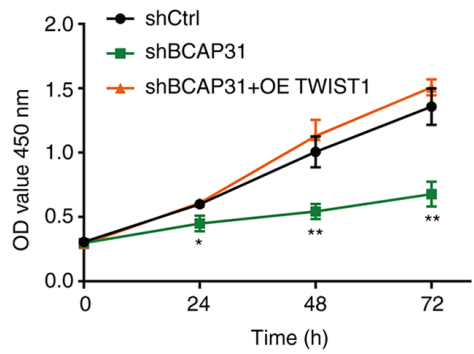

D

C
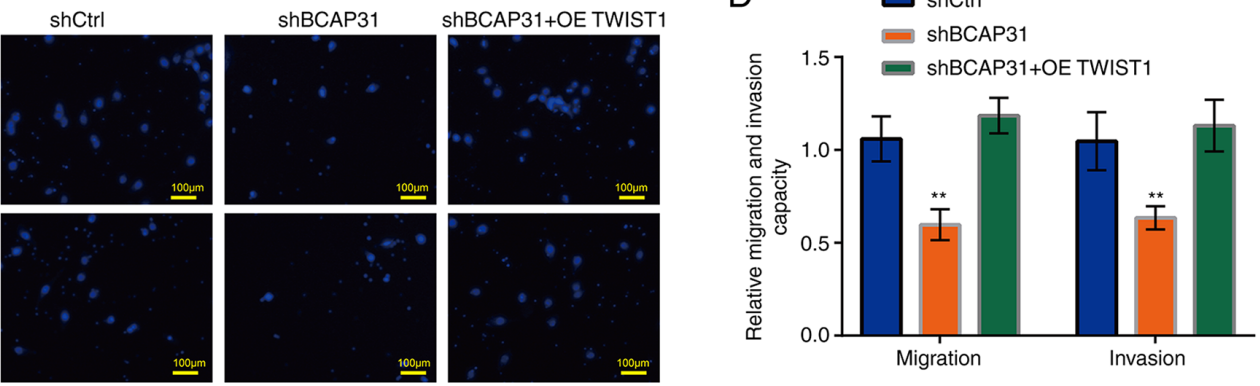

E

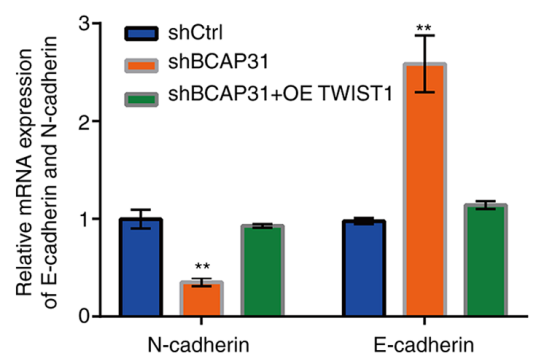

F

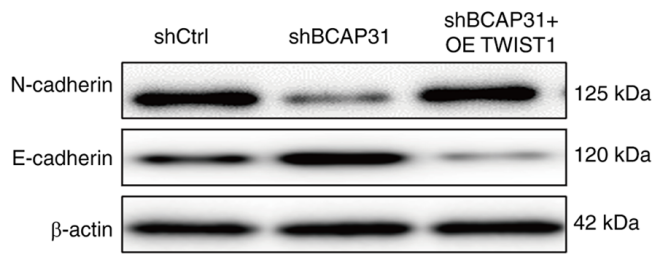

Figure 5. Cell functions and EMT-related protein expression levels are recovered when TWIST1 was overexpressed in the shBCAP31 A2780 cells. (A) Protein expression of TWIST1 in the cytoplasmic and nuclear fractions of shCtrl, shBCAP31 and shBCAP31 + OE TWIST1 A2780 cells. (B) Growth curve after transfection with shCtrl, shBCAP31 and shBCAP31 + OE TWIST1. (C) Representative Transwell assay images of migratory and invasive shCtrl, shBCAP31 and shBCAP31 + OE TWIST1 A2780 cells. (D) Relative migratory and invasive abilities of shCtrl, shBAP31 and shBAP31 + OE TWIST1 A2780 cells. (E) mRNA and (F) protein expression of N-cadherin and E-cadherin in shCtrl, shBCAP31 and shBCAP31 + OE TWIST1 A2780 cells. ${ }^{*} \mathrm{P}<0.05,{ }^{* *} \mathrm{P}<0.01$ vs. shCtrl. BCAP31, B cell receptor-associated protein 31; sh, short hairpin RNA; OE, overexpression; Ctrl, control; OD, optical density; CDH cadherin.

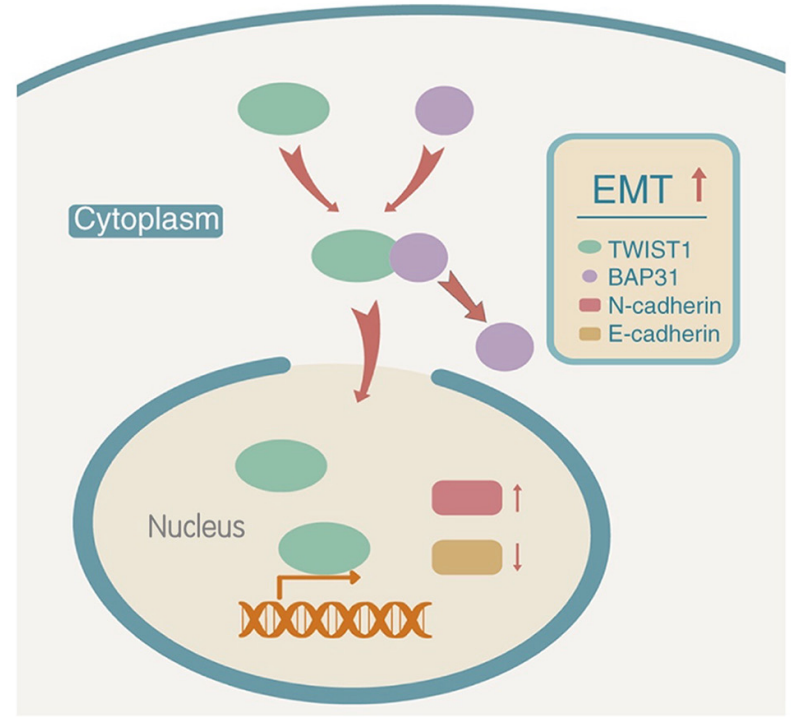

Figure 6. Schematic diagram of the possible role of BAP31 in ovarian cancer. BAP31 regulates the expression of E-cadherin and N-cadherin at the transcriptional level by promoting the degree of TWIST1 nucleus aggregation of. BAP31, B cell receptor-associated protein 31; EMT, epithelial-mesenchymal transition. regulate the metabolism of a number of proteins $(10,48-50)$. BAP31 can also function as a carrier protein to mediate the transport of proteins from the ER to the Golgi apparatus for processing and maturation (11).

BAP31 is located in the ER, where the cleaved fragment, BAP20, serves an important role in apoptosis (11). BAP20 induces the ER to release $\mathrm{Ca}^{2+}$, which is taken up by the mitochondria, leading to mitochondrial fragmentation and subsequent cell death (11). By contrast, the complete BAP31 protein is a direct inhibitor of caspase 8, which initiates apoptosis (51). BAP31 is highly expressed in various cancer tissues, including breast, cervical, liver and colorectal cancer (15-18). Therefore, the BAP31 protein and mRNA expression profile in ovarian cancer cells was investigated in the present study.

A previous study demonstrated that BAP31 is a key gene that promotes the progression of triple negative breast cancer, where it can interact with epidermal growth factor receptor (EGFR) to maintain EGFR autophosphorylation and downstream signal activation (52). In another study, downregulation of BAP31 expression can inhibit the proliferation and increase apoptosis of colorectal cancer cells by increasing the expression of ER-related proteins, including GRP78/BIP, BAX and 
PERK/elF2 $\alpha /$ ATF4/CHOP (53). BAP31 expression has also been found to be significantly increased in cervical cancer tissue compared with adjacent normal tissue and associated highly with poorer clinical outcomes $(16,18)$. In addition, BAP31 can regulate cervical cancer cell proliferation by arresting $\mathrm{G}_{0} / \mathrm{G}_{1}$ phase cell cycle progression in cervical cancer cells (18). Depletion of BAP31 can also inhibit the invasion and migration of cervical cancer cells by decreasing the expression and uniform distribution in the cel of Drebrin, myosin phosphatase Rho-interacting protein, calcium-binding protein SPEC 1A and Nexilin (18). The expression levels of transforming growth factor- $\beta 1$, matrix metalloproteinase (MMP)-2, MMP-9, rho-related protein kinase 1, $\alpha$-SMA, vimentin and $\mathrm{N}$-cadherin were found to be significantly lower in cervical cancer cells following the knockdown of BAP31 expression (16). Furthermore, the extent intrinsic and extrinsic apoptosis was notably increased in cells following BAP31 knockdown with the increased levels of cleaved caspases-8, -9 and -3 in addition to poly (ADP-ribose) polymerase (16). However, another study reported that BAP31 can stimulate U2OS osteosarcoma and HeLa cervical cancer cell death and inhibit autophagy by interacting with syntaxin 17 to form a protein complex under ER-stress conditions (49). These previous findings aforementioned demonstrated that BAP31 can serve different roles under diverse conditions. To investigate the role of BAP31 in ovarian cancer in the present study, a shBCAP31 lentiviral vector was constructed before the ovarian cancer cell lines A2780 and Hey-T30 were transfected after viral packaging to construct the shBCAP31 cell line. It was found that the viability of A2780 and Hey-T30 cells was decreased markedly following the knockdown of BAP31. The migration and invasion of shBCAP31 cells were also inhibited compared with those in cells in the shCtrl group. These results suggest that BAP 31 may have an important role in the migration and invasion of ovarian cancer cells.

To explore the specific mechanism underlying the effects of BAP31 on ovarian cancer cells, RNA-seq analysis was performed in the present study to detect the differences in gene transcription between shBCAP31 and shCtrl cells. E-cadherin and $\mathrm{N}$-cadherin, two key markers in the EMT process (21), were markedly upregulated and downregulated following BAP31 knockdown, respectively. This was also confirmed by RT-qPCR and western blotting. EMT is a process in which epithelial cells lose their intercellular connections and acquire a more migratory and aggressive mesenchymal phenotype (54). However, this process serves a vital role during normal development in addition to various forms of tumorigenesis (55). In addition, EMT has been reported to serve an important role in the metastasis of a majority of human tumors $(20,56)$, which can be used as an early indicator of tumor invasion and metastasis (57). Results from the present study suggest that the EMT pathway may be manipulated by altering the expression of BAP31 in ovarian cancer. Cell viability, migration and invasion of the shBCAP31 ovarian cancer cell lines were all markedly downregulated, which could be due to inhibition of the EMT pathway in the shBCAP31 cell line.

Compared with cell lines that express high levels of $\mathrm{N}$-cadherin, ovarian cancer cell lines with high expression levels of E-cadherin exhibit poor resistance to cell death, reduced adhesion to the extracellular matrix and weaker invasiveness (58). As an indicator of ongoing EMT, expression of $\mathrm{N}$-cadherin is associated with the development of various types of tumors, such as prostate (59) and non-small cell lung cancer (60). During EMT in cancer, $\mathrm{N}$-cadherin is frequently upregulated, whilst E-cadherin is downregulated. This cadherin switch is concomitant with enhanced cell migration and invasion, resulting in the lower survival rate of patients (61). The present study showed that BAP31 altered the expression of E-cadherin and $\mathrm{N}$-cadherin simultaneously in ovarian cancer cells. However, this was not a result of the direct interaction between BAP31 and E- and N-cadherin, which was not observed. There was a clear interaction between E-cadherin and $\mathrm{N}$-cadherin, suggesting that there may be a direct mutual regulatory mechanism between E-cadherin and $\mathrm{N}$-cadherin. These results are consistent with previous findings (21) that demonstrated that 'cadherin switch' (N-cadherin is upregulation and $\mathrm{E}$-cadherin downregulation during the EMT process in cancer), is associated with enhanced migration and invasion. Since the knockdown of BAP31 affected the expression of $\mathrm{E}$-cadherin and $\mathrm{N}$-cadherin on a transcriptional level, it was speculated that the expression or transcriptional activity of TFs that regulate E-cadherin and $\mathrm{N}$-cadherin expression were influenced by BAP31.

The present study found that the expression of E-cadherin was upregulated, whereas the expression of $\mathrm{N}$-cadherin was downregulated, in cells transfected with siTWIST1, which is consistent with the expression of these two genes analyzed by RNA-seq in BCAP31 cells. Further analysis revealed an interaction between BAP31 and TWIST1, where the degree of TWIST1 aggregation in the nucleus decreased markedly following the knockdown of BAP31 expression. TWIST1 is a highly conserved basic helix-loop-helix TF that has been previously identified to be a developmental gene and serves a key role in E-cadherin inhibition and EMT induction (62). In addition to having an important role in normal development, TWIST was found to be upregulated in numerous types of cancer, including breast $(35,41)$, gastric $(40,63)$ and prostate cancer $(64)$. In vertebrates, two structurally similar isoforms are expressed, namely TWIST1 and TWIST2 (37). TWIST1 contains a glycine-rich region, which may serve a role in RNA binding, at the N-terminus, whilst TWIST2 does not (37). In intestinal gastric cancer, the highly expressed TWIST1 protein enhances the aggressiveness of gastric cancer cells by downregulating the expression of E-cadherin and upregulating the expression of N-cadherin (63). In the present study, when TWIST1 was overexpressed in the shBCAP31 cells, cell proliferation, migration and invasion were restored to the levels comparable to those of shCtrl cells. Additionally, the mRNA and protein expression levels of E-cadherin and $\mathrm{N}$-cadherin were comparable to those observed in the shCtrl group. These findings suggest that BAP31 may regulate the expression of E-cadherin and $\mathrm{N}$-cadherin through the subcellular location of TWIST1, one of the TFs that mediate EMT, which in turn regulates the proliferation, migration and invasion of ovarian cancer cells (Fig. 6). Therefore, BAP31 may promote the EMT pathway by affecting the nuclear and cytoplasmic distribution of TWIST1 in ovarian cancer cells.

To conclude, results of the present study showed that BAP31 expression was upregulated in ovarian cancer cells, suggesting that BAP31 promoted the proliferation, migration 
and invasion of ovarian cancer cells. Knockdown of BAP31 was found to increase the expression of E-cadherin and decrease the expression of $\mathrm{N}$-cadherin, two markers of the EMT pathway. Concurrently, BAP31 regulated the expression of E-cadherin and N-cadherin on transcriptional level by affecting the degree of nuclear TWIST1 aggregation, one of the TFs that can regulate the mRNA expression of E-cadherin and $\mathrm{N}$-cadherin. These findings suggested that BAP31 serve a carcinogenic role in ovarian cancer, which provide theoretical evidence for the role of BAP31 as a biomarker in patients with ovarian cancer.

\section{Acknowledgements}

Not applicable.

\section{Funding}

This study was supported by the National Natural Science Foundation of China (grant nos. 81372777 and 81372779).

\section{Availability of data and materials}

The datasets generated and/or analyzed during the current study are available in the NCBI repository (BioProject ID PRJNA731548).

\section{Authors' contributions}

DF and BL designed the study. HL, DF and BL analyzed the data. HL wrote the manuscript. JD, ZC, HL and QL performed the experiments and collected the data. HL and JD confirm the authenticity of all the raw data. All authors read and approved the final manuscript.

\section{Ethics approval and consent to participate}

The use of human tissue was approved by the Ethics Committee of China-Japan Friendship Hospital (approval no. 2020-28-K20)and written informed consents were obtained from all participants.

\section{Patient consent for publication}

Not applicable.

\section{Competing interests}

The authors declare that they have no competing interests.

\section{References}

1. Siegel RL, Miller KD and Jemal A: Cancer statistics, 2020. CA Cancer J Clin 70: 7-30, 2020.

2. Su Z, Graybill WS and Zhu Y: Detection and monitoring of ovarian cancer. Clin Chim Acta 415: 341-345, 2013.

3. Torre LA, Trabert B, DeSantis CE, Miller KD, Samimi G, Runowicz CD, Gaudet MM, Jemal A and Siegel RL: Ovarian cancer statistics, 2018. CA Cancer J Clin 68: 284-296, 2018

4. Narod S: Can advanced-stage ovarian cancer be cured. Nat Rev Clin Oncol 13: 255-261, 2016.

5. Lim D and Oliva E: Precursors and pathogenesis of ovarian carcinoma. Pathology 45: 229-242, 2013
6. Vang R, Shih IeM and Kurman RJ: Ovarian low-grade and high-grade serous carcinoma: Pathogenesis, clinicopathologic and molecular biologic features, and diagnostic problems. Adv Anat Pathol 16: 267-282, 2009.

7. Nelson BH: The impact of T-cell immunity on ovarian cancer outcomes. Immunol Rev 222: 101-116, 2008.

8. Kim KM, Adachi T, Nielsen PJ, Terashima M, Lamers MC, Köhler G and Reth M: Two new proteins preferentially associated with membrane immunoglobulin D. EMBO J 13: 3793-3800, 1994.

9. Adachi T, Schamel WW, Kim KM, Watanabe T, Becker B, Nielsen PJ and Reth M: The specificity of association of the $\operatorname{IgD}$ molecule with the accessory proteins BAP31/BAP29 lies in the IgD transmembrane sequence. EMBO J 15: 1534-1541, 1996.

10. Namba T, Tian F, Chu K, Hwang SY, Yoon KW, Byun S, Hiraki M, Mandinova A and Lee SW: CDIP1-BAP31 complex transduces apoptotic signals from endoplasmic reticulum to mitochondria under endoplasmic reticulum stress. Cell Rep 5: 331-339, 2013.

11. Breckenridge DG, Stojanovic M, Marcellus RC and Shore GC: Caspase cleavage product of BAP31 induces mitochondrial fission through endoplasmic reticulum calcium signals, enhancing cytochrome $c$ release to the cytosol. J Cell Biol 160: 1115-1127, 2003.

12. Wakana Y, Takai S, Nakajima K, Tani K, Yamamoto A, Watson $P$, Stephens DJ, Hauri HP and Tagaya M: Bap31 is an itinerant protein that moves between the peripheral endoplasmic reticulum (ER) and a juxtanuclear compartment related to ER-associated Degradation. Mol Biol Cell 19: 1825-1836, 2008.

13. Matroule JY, Carthy CM, Granville DJ, Jolois O, Hunt DW and Piette J: Mechanism of colon cancer cell apoptosis mediated by pyropheophorbide-a methylester photosensitization. Oncogene 20: 4070-4084, 2001.

14. Yu S, Wang F, Fan L, Wei Y, Li H, Sun Y, Yang A, Jin B, Song C and Yang K: BAP31, a promising target for the immunotherapy of malignant melanomas. J Exp Clin Cancer Res 34: 36, 2015.

15. Tan N, Liu Q, Liu X, Gong Z, Zeng Y, Pan G, Xu Q and He S: Low expression of B-cell-associated protein 31 in human primary hepatocellular carcinoma correlates with poor prognosis. Histopathology 68: 221-229, 2016.

16. Wang A, Zhang Y and Cao P: Inhibition of BAP31 expression inhibits cervical cancer progression by suppressing metastasis and inducing intrinsic and extrinsic apoptosis. Biochem Biophys Res Commun 508: 499-506, 2019.

17. Ma C, Jin RM, Chen KJ, Hao T, Li BS, Zhao DH and Jiang H: Low expression of B-Cell-Associated protein 31 is associated with unfavorable prognosis in human colorectal cancer. Pathol Res Pract 214: 661-666, 2018.

18. Dang E, Yang S, Song C, Jiang D, Li Z, Fan W, Sun Y, Tao L, Wang J, Liu T, et al: BAP31, a newly defined cancer/testis antigen, regulates proliferation, migration, and invasion to promote cervical cancer progression. Cell Death Dis 9: 791, 2018.

19. Nieto MA, Huang RY, Jackson RA and Thiery JP: EMT: 2016. Cell 166: 21-45, 2016.

20. Thiery JP, Acloque H, Huang RY and Nieto MA: Epithelial-mesenchymal transitions in development and disease. Cell 139: 871-890, 2009.

21. Loh CY, Chai JY, Tang TF, Wong WF, Sethi G, Shanmugam MK, Chong PP and Looi CY: The E-cadherin and N-cadherin switch in epithelial-to-mesenchymal transition: Signaling, therapeutic implications, and challenges. Cells 8: 1118, 2019.

22. Ling ZQ, Li P, Ge MH, Zhao X, Hu FJ, Fang XH, Dong ZM and Mao WM: Hypermethylation-modulated down-regulation of $\mathrm{CDH} 1$ expression contributes to the progression of esophageal cancer. Int J Mol Med 27: 625-635, 2011.

23. Umbas R, Schalken JA, Aalders TW, Carter BS, Karthaus HF, Schaafsma HE, Debruyne FM and Isaacs WB: Expression of the cellular adhesion molecule E-cadherin is reduced or absent in high-grade prostate cancer. Cancer Res 52: 5104-5109, 1992.

24. Petrova YI, Schecterson L and Gumbiner BM: Roles for E-cadherin cell surface regulation in cancer. Mol Biol Cell 27: 3233-3244, 2016

25. Fransvea E, Angelotti U, Antonaci S and Giannelli G: Blocking transforming growth factor-beta up-regulates E-cadherin and reduces migration and invasion of hepatocellular carcinoma cells. Hepatology 47: 1557-1566, 2008.

26. Tang G, Du R, Tang Z and Kuang Y: MiRNALet-7a mediates prostate cancer PC-3 cell invasion, migration by inducing epithelial-mesenchymal transition through CCR7/MAPK pathway. J Cell Biochem 119: 3725-3731, 2018. 
27. del Valle I, Rudloff S, Carles A, Li Y, Liszewska E, Vogt R and Kemler R: E-cadherin is required for the proper activation of the Lifr/Gp130 signaling pathway in mouse embryonic stem cells. Development 140: 1684-1692, 2013.

28. Hazan RB, Qiao R, Keren R, Badano I and Suyama K: Cadherin switch in tumor progression. Ann N Y Acad Sci 1014: 155-163, 2004

29. Muramaki M, Miyake H, Terakawa T, Kumano M, Sakai I and Fujisawa M: Expression profile of E-cadherin and N-cadherin in non-muscle-invasive bladder cancer as a novel predictor of intravesical recurrence following transurethral resection. Urol Oncol 30: 161-166, 2012.

30. Shintani Y, Hollingsworth MA, Wheelock MJ and Johnson KR: Collagen I promotes metastasis in pancreatic cancer by activating c-Jun NH(2)-terminal kinase 1 and up-regulating N-cadherin expression. Cancer Res 66: 11745-11753, 2006.

31. Puisieux A, Brabletz T and Caramel J: Oncogenic roles of EMT-inducing transcription factors. Nat Cell Biol 16: 488-494, 2014.

32. Hamamori Y, Wu HY, Sartorelli V and Kedes L: The basic domain of myogenic basic helix-loop-helix (bHLH) proteins is the novel target for direct inhibition by another bHLH protein, Twist. Mol Cell Biol 17: 6563-6573, 1997.

33. Lee MS, Lowe GN, Strong DD, Wergedal JE and Glackin CA: TWIST, a basic helix-loop-helix transcription factor, can regulate the human osteogenic lineage. J Cell Biochem 75: 566-577, 1999.

34. Verzi MP, Anderson JP, Dodou E, Kelly KK, Greene SB North BJ, Cripps RM and Black BL: N-twist, an evolutionarily conserved bHLH protein expressed in the developing CNS, functions as a transcriptional inhibitor. Dev Biol 249: 174-190, 2002.

35. Mironchik Y, Winnard PT Jr, Vesuna F, Kato Y, Wildes F Pathak AP, Kominsky S, Artemov D, Bhujwalla Z, Van Diest $\mathrm{P}$, et al: Twist overexpression induces in vivo angiogenesis and correlates with chromosomal instability in breast cancer. Cancer Res 65: 10801-10809, 2005.

36. Ansieau S, Bastid J, Doreau A, Morel AP, Bouchet BP, Thomas C, Fauvet F, Puisieux I, Doglioni C, Piccinin S, et al: Induction of EMT by twist proteins as a collateral effect of tumor-promoting inactivation of premature senescence. Cancer Cell 14: 79-89, 2008.

37. Rodriguez Y, Gonzalez-Mendez RR and Cadilla CL: Evolution of the twist subfamily vertebrate proteins: Discovery of a signature motif and origin of the twistl glycine-rich motifs in the amino-terminus disordered domain. PLoS One 11: e0161029, 2016

38. Ansieau S, Morel AP, Hinkal G, Bastid J and Puisieux A: TWISTing an embryonic transcription factor into an oncoprotein. Oncogene 29: 3173-3184, 2010.

39. Satoh K, Hamada S, Kimura K, Kanno A, Hirota M, Umino J, Fujibuchi W, Masamune A, Tanaka N, Miura K, et al Up-regulation of MSX2 enhances the malignant phenotype and is associated with twist 1 expression in human pancreatic cancer cells. Am J Pathol 172: 926-939, 2008.

40. Ru GQ, Wang HJ, Xu WJ and Zhao ZS: Upregulation of Twist in gastric carcinoma associated with tumor invasion and poor prognosis. Pathol Oncol Res 17: 341-347, 2011.

41. Ranganathan S, Krishnan A and Sivasithambaram ND Significance of twist and iNOS expression in human breast carcinoma. Mol Cell Biochem 412: 41-47, 2016.

42. Khan MA, Chen HC, Zhang D and Fu J: Twist: A molecular target in cancer therapeutics. Tumour Biol 34: 2497-2506, 2013.

43. Lu Z and Chen J: Introduction of WHO classification of tumours of female reproductive organs, fourth edition. Zhonghua Bing $\mathrm{Li}$ Xue Za Zhi 43: 649-650, 2014 (In Chinese).

44. Livak KJ and Schmittgen TD: Analysis of relative gene expression data using real-time quantitative PCR and the 2(-Delta Delta C(T)) method. Methods 25: 402-408, 2001

45. Wang L, Feng Z, Wang X, Wang X and Zhang X: DEGseq: An $\mathrm{R}$ package for identifying differentially expressed genes from RNA-seq data. Bioinformatics 26: 136-138, 2010.

46. Scanlon CS, Van Tubergen EA, Inglehart RC and D'Silva NJ: Biomarkers of epithelial-mesenchymal transition in squamous cell carcinoma. J Dent Res 92: 114-121, 2013.
47. Malgulwar PB, Nambirajan A, Pathak P, Rajeshwari M, Suri V, Sarkar C, Singh M and Sharma MC: Epithelial-to-mesenchymal transition-related transcription factors are up-regulated in ependymomas and correlate with a poor prognosis. Hum Pathol 82: 149-157, 2018.

48. Namba T: BAP31 regulates mitochondrial function via interaction with Tom40 within ER-mitochondria contact sites. Sci Adv 5: eaaw1386, 2019.

49. Machihara K and Namba T: BAP31 inhibits cell adaptation to ER stress conditions, negatively regulating autophagy induction by interaction with STX17. Cells 8: 1350, 2019.

50. Quistgaard EM: BAP31: Physiological functions and roles in disease. Biochimie 186: 105-129, 2021.

51. Wilson JD and Barlowe C: Yet1p and Yet3p, the yeast homologs of BAP29 and BAP31, interact with the endoplasmic reticulum translocation apparatus and are required for inositol prototrophy. J Biol Chem 285: 18252-18261, 2010.

52. Fu W, Sun H, Zhao Y, Chen M, Yang X, Liu Y and Jin W: BCAP31 drives TNBC development by modulating ligand-independent EGFR trafficking and spontaneous EGFR phosphorylation. Theranostics 9: 6468-6484, 2019.

53. Xu K, Han B, Bai Y, Ma XY, Ji ZN, Xiong Y, Miao SK, Zhang YY and Zhou LM: MiR-451a suppressing BAP31 can inhibit proliferation and increase apoptosis through inducing ER stress in colorectal cancer. Cell Death Dis 10: 152, 2019.

54. Thiery JP: Epithelial-mesenchymal transitions in tumour progression. Nat Rev Cancer 2: 442-454, 2002.

55. Shook D and Keller R: Mechanisms, mechanics and function of epithelial-mesenchymal transitions in early development. Mech Dev 120: 1351-1383, 2003.

56. Yun SJ and Kim WJ: Role of the epithelial-mesenchymal transition in bladder cancer: From prognosis to therapeutic target. Korean J Urol 54: 645-650, 2013

57. Franco-Chuaire ML, Magda Carolina SC and Chuaire-Noack L: Epithelial-mesenchymal transition (EMT): Principles and clinical impact in cancer therapy. Invest Clin 54: 186-205, 2013.

58. Rosso M, Majem B, Devis L, Lapyckyj L, Besso MJ, Llauradó M, Abascal MF, Matos ML, Lanau L, Castellví J, et al: E-cadherin: A determinant molecule associated with ovarian cancer progression, dissemination and aggressiveness. PLoS One 12: e0184439, 2017.

59. Wang M, Ren D, Guo W, Huang S, Wang Z, Li Q, Du H, Song L and Peng X: N-cadherin promotes epithelial-mesenchymal transition and cancer stem cell-like traits via ErbB signaling in prostate cancer cells. Int J Oncol 48: 595-606, 2016.

60. Hui L, Zhang S, Dong X, Tian D, Cui Z and Qiu X: Prognostic significance of twist and $\mathrm{N}$-cadherin expression in NSCLC. PLoS One 8: e62171, 2013.

61. Araki K, Shimura T, Suzuki H, Tsutsumi S, Wada W, Yajima T, Kobayahi T, Kubo N and Kuwano H: E/N-cadherin switch mediates cancer progression via TGF- $\beta$-induced epithelial-to-mesenchymal transition in extrahepatic cholangiocarcinoma. Br J Cancer 105: 1885-1893, 2011

62. Yang J, Mani SA, Donaher JL, Ramaswamy S, Itzykson RA, Come C, Savagner P, Gitelman I, Richardson A and Weinberg RA: Twist, a master regulator of morphogenesis, plays an essential role in tumor metastasis. Cell 117: 927-939, 2004.

63. Rosivatz E, Becker I, Specht K, Fricke E, Luber B, Busch R, Höfler $\mathrm{H}$ and Becker KF: Differential expression of the epithelial-mesenchymal transition regulators snail, SIP1, and twist in gastric cancer. Am J Pathol 161: 1881-1891, 2002.

64. Kwok WK, Ling MT, Lee TW, Lau TC, Zhou C, Zhang X, Chua CW, Chan KW, Chan FL, Glackin C, et al: Up-regulation of TWIST in prostate cancer and its implication as a therapeutic target. Cancer Res 65: 5153-5162, 2005. 